\title{
Orogenic quiescence in Earth's middle
}

\section{age}

MING TANG ${ }^{1}, \mathrm{XU} \mathrm{CHU}^{2}$, JIHUA HAO $^{3}$ AND BING SHEN ${ }^{1}$

${ }^{1}$ Peking University

${ }^{2}$ University of Toronto

${ }^{3}$ University of Science and Technology of China

Presenting Author: mingtang@pku.edu.cn

Mountain belts modulate denudation flux and hydrologic processes and are thus fundamental to nutrient cycling on Earth's surface [1-4]. However, due to the lack of continuous and consistent records of orogenesis over Earth's history, the role of this tectonic forcing in shaping the secular evolution of Earth's surface environment remains elusive. Here we use europium anomalies in detrital zircons to reconstruct the evolution of crustal thickness, which reflects mountain building activity, over the last 4.5 billion years. We show that the average thickness of active continental crust varied significantly on billion-year timescales with the thickest crust formed in the Archean and Phanerozoic. By contrast, the Proterozoic witnessed a continuous decline in crustal thickness for over a billion years, leaving the continents devoid of high mountains until the end of the eon. We link the low mountain building activity in the Proterozoic to the long-lived Nuna-Rodinia supercontinent, which could significantly alter the thermal structure of the mantle, affected the operation of plate tectonics, and weakened the continental lithosphere. This prolonged quiescence in mountain building may have resulted in a persistent famine in the oceans and stalled life's evolution in Earth's middle age.

References

[1] Barley, Bekker \& Krapež (2005), Earth and Planetary Science Letters 238, 156-171.

[2] West, Galy \& Bickle (2005), Earth and Planetary Science Letters 235, 211-228.

[3] Lee \& Lackey (2015), Elements 11, 125-130.

[4] Larsen, Montgomery \& Greenberg (2014), Geology 42, 527-530. 